\title{
Determinants of Gestational Age at Termination of Pregnancy in the Capital City of Ghana (Accra)
}

\author{
Fred Yao Gbagbo \\ Marie Stopes International, Ghana \\ gbagbofredyao2002@yahoo.co.uk
}

\begin{abstract}
Empirical and anecdotal evidence indicate that the gestation of a pregnancy at termination in Ghana can be influenced by circumstances surrounding onset of pregnancy or challenges arising during pregnancy. This study examined determinants of gestational age at termination of pregnancy in Accra, Ghana. The study design was cross-sectional and used a mixed-method approach. Four hundred and one (401) women who had induced abortion in designated hospitals between January and December 2010 were randomly sampled and interviewed using interviewer-administered questionnaires. Additional 30 women were engaged in in-depth interviews. Descriptive and multinomial logistic regression analyses were used to analyze the quantitative data. The qualitative data was thematically analyzed based on responses obtained. The study found that, about76\% of respondents had an abortion during the first trimester (1-3 months) of pregnancy. Marital status $\left(\square^{2}=29.59 ; p<0.001\right)$ and age $\left(\square^{2}=32.71 ; p=0.008\right)$ were significantly associated with gestations at termination. Persons responsible for a pregnancy were noted to have influenced gestations at termination. Midtrimester abortion (4+ months) decisions were painfully taken to escape situations that negatively affected respondents' health, education, social life and/or carrier development goals. There was significant associations $(O R=1.47 ; 95 \% C I=0.488-4.413)$ between occupation and gestation at termination. Pregnant women who are students/apprentices are more likely (-2log-likelihood of -100.7) to have an abortion at an earlier gestations than women of other occupation categories mainly to avoid workplace/institutional sanctions. Women need education and support on gestations for safe abortion as permitted by the Ghanaian abortion law. Ultimately, public health policies and women's right dialogues should frown on workplace/institutional sanctions on pregnancy that push women to have an abortion against their wish and regardless of the gestation to achieve their carrier and reproductive intentions. This may contribute directly to a decrease in unsafe abortion fatalities in Ghana.
\end{abstract}

Keywords: Abortion, Determinants, Ghana, Gestation, Termination

\section{INTRODUCTION}

Every year, about 205 million women worldwide become pregnant and nearly one in five (40-50 million) choose to terminate the pregnancy for various reasons ${ }^{1}$ This figure corresponds to approximately 125,000 abortions per day of which close to 20 million are estimated to be unsafe ${ }^{2,3}$ Globally induced abortion rates have slightly changed between 2003 and 2008. ${ }^{4}$ This is due to improved access to family planning education and contraception. ${ }^{5}$ As of 2008 , forty percent of the world's women had access to legally permitted induced abortions ${ }^{4}$ In Countries where induced abortion is legally permitted there are gestational limits at which a pregnancy can be legally terminated ${ }^{5}$

The policy and legal issues surrounding pregnancy termination, how frequently termination is done, and their cultural and religious status vary a great deal around the world. In some contexts, abortion is legal based on specific conditions, such as incest, rape, gross feotal abnormalities, socio-economic factors or the risk to a mother's health. ${ }^{6}$ In many parts of the world there is prominent public controversy over the moral, ethical, and legal issues of abortion. Those who are against abortion generally state that an embryo or fetus is a human with the right to life and may compare abortion to murder. ${ }^{7,8}$ Those who support abortion rights emphasize a woman's right to decide matters concerning her own body ${ }^{9}$ as well as emphasizing human rights generally. ${ }^{6}$

Ghana has a legal and policy framework that technically defines, induced abortion as the termination of pregnancy before the feotus becomes viable. The viability is however up to 28 weeks of gestation so as to regulate gestations at pregnancy termination for client safety among others ${ }^{10,11}$ The general situation however is that, once a woman becomes pregnant; her body no longer becomes hers. Many at this stage are at the mercy of health workers, family members, sexual partners and/or significant 
others who influence the gestation at which a pregnancy is terminated and sometimes at the detriment of the pregnant woman ${ }^{12}$. Nevertheless, different views therefore quickly come to the fore to justify an induced abortion and women with varying profiles make decisions to terminate pregnancies regardless of gestational limitations ${ }^{13}$.

This paper first presents the profile of abortion seekers and further examines the determinants of gestational age of pregnancy at termination among women who had an induced abortion in a cosmopolitan urban setting in Ghana. The paper aim to present evidence in the area of induced abortion that will inform reproductive health policy makers and clinicians on varying reasons behind gestations at pregnancy termination for appropriate policy and programme interventions to ensure safer abortions.

\section{Materials AND Methods}

\subsection{Selecting of Study Sites}

The current study was conducted in four purposively selected Reducing Maternal Mortality and Morbidity (R3M) accredited abortion service providers in the Accra Metropolis. The estimated population of the Accra metropolis as of 2010 was 2,242,505 of which about 841,533 were women within the reproductive ages ${ }^{14}$ As of 2010 , there were 481 health facilities in the Accra Metropolis comprising four government hospitals, 7 polyclinics, four quasi government hospitals, 49 private hospitals, 270 clinics, 39 company clinics, 79 private maternity homes and 29 NGO/Mission hospitals $^{15}$ The Ghana Health Service in collaboration with a consortium of five multinational organizations (Engender Health, Ipas, Marie Stopes International, Population Council, and the Willows Foundation), initiated the R3M project in the Greater Accra, Eastern and Ashanti regions following initial piloting in 17 districts in 2007.

The R3M provides financial and technical assistance to enable the government to significantly expand women's access to modern family planning (FP) and comprehensive abortion care (CAC) as permitted by the Ghanaian laws ${ }^{16}$. The Accra Metropolis, which was one of the pilot districts, was purposively selected for this study because of its role as the national capital with people of varied backgrounds. Four facilities namely Marie Stopes International centre (an NGO facility), Marie Stopes franchisees called BlueStar HealthCare Network facilities [private for-profit], the La and Ridge hospitals (public hospitals), which were part of the 17 facilities used for the piloting, were purposively selected based on the high numbers and quality of abortion services reported in the study area.

\subsection{Research Design}

The study was cross-sectional in nature employing both qualitative and quantitative data collecting methods so as to complement the strengths of each method and mitigate the limitations of the respective paradigms of using both questionnaires and in-depth interview (IDI) guides ${ }^{13,14}$ Although findings of the study are presented concurrently, both the qualitative and the quantitative data were given equal weights for better understanding of the key findings. The questionnaire ${ }^{14,15}$ and IDI guides ${ }^{13}$ were adapted from previous abortion studies in Ghana. The field work was conducted between June and December 2011

\subsection{Selection of Participants for Quantitative Data}

A questionnaire which was structured around factors influencing gestations at pregnancy termination was used for the quantitative data collection. The data collection process used a retrospective crosssectional approach. Because the quantitative data collected aimed to provide information on the determinants of gestations at termination an interviewer-administered questionnaire was used to obtain the quantitative data. The study based the sample size calculations on $95 \%$ confidence interval, $5 \%$ margin of error and 50\% response distribution. A total of 410 women were sampled from a frame of 9,494 obtained from the four abortion providers. Population proportional to size method was employed to allocate samples to the four facilities. The sample was distributed among the facilities as follows: Marie Stopes (61), BlueStar (217), Ridge (53) and La (39) hospitals. Individual respondents were randomly selected from the abortion register. In situations where a randomly selected respondent refused to participate in the study, another person on the register was randomly selected and the procedure continued until the desired sample size estimated for the study was achieved. 


\subsection{Selection of Participants for IDIs}

The main objective of collecting qualitative data was to compliment information obtained using the quantitative tool. This was to enable the researcher to discover more meanings and explanations into the question of why some pregnancies are terminated earlier whereas others are terminated at very advanced gestations. For the IDI, 30 respondents consisting of 10 previously married women, 10 unmarried women and 10 married women were randomly selected to further explore what informed the gestation at terminating a pregnancy. These women whose telephone contacts were found in the abortion register in the health facilities and willing to participate in the study were invited by service providers in the respective facilities where they had their terminations to participate in the in-depth interviews.

The IDI guide which was unstructured, focused on circumstances surrounding onset of pregnancy, initial reactions to pregnancy, perceived partner support, carrier progression, socio-economic status and health risk of pregnancy to a pregnant woman. Respondents who had already participated in the survey questionnaire were excluded from the IDI to avoid research fatigue and emotional breakdown as they have to recall a challenging past. The interviews were conducted one-on-one and each interview took an average of 40 minutes. Both questionnaires and IDI guide were available in English but were translated into local languages for respondents who could not speak English. Ten trained nurses served as research assistants.

\subsection{Ethical Considerations During Data Collection and Analysis}

Although the Ethics Review Committee of Ghana Health Service reviewed and approved the study (GHS-ERC: 11/01/11), permission for community entry was obtained from the Accra Metropolitan Health Directorate before the field interviews commenced. All interviews were conducted after a respondent had informed consent and voluntarily consented to participate in the study. Respondents had the right to withdraw their consent of participation from elements of the study or from the study entirely at any time without any coercion. All interviews were conducted on individual basis at a place away from ear short of others. Names, physical contact addresses and telephone numbers of respondents were documented separately and were not captured on the research instruments or in the data set to ensure strict anonymity so that no third party could trace information provided during the interviews to a respondent.

The likelihood that some field assistants or respondents may have some emotional distress, or become uncomfortable having an interview on a morally sensitive issue of abortion was anticipated. The study was therefore designed to have this minimized by administering a short interview in a strictly nonjudgmental manner. Two respondents who became emotional during interviews were referred to preidentified trained counselors at the Ridge hospital and Marie Stopes centres for appropriate counseling support. Although no monetary incentives were given to any of the respondents a non-monetary token of 10 Ghana cedis worth of individual respondent's preferred mobile phone credit was provided each respondent after being interviewed so as to facilitate communication relating to the study after the interview to address any follow-up concerns.

\section{Data Analysis}

\subsection{Quantitative Data Analysis}

The quantitative data was analyzed on two main thematic areas relating to pregnancy termination (i.e profile of women who had induced abortion and gestation at termination). Descriptive statistics with corresponding Chi-Square values were derived, followed by multinomial regression. Multinomial regression was used for inferential analysis because the dependent variables (i.e profile of women and gestation at termination) had more than two outcomes, which makes it the most appropriate statistical tool for isolating the independent effects of the various categories of the background factors of abortion-seekers in abortion decision-making on gestation at termination. The back ground factors captured in the quantitative data were occupation, age, marital status, religion, ethnicity, parity and number of previous abortions. These variables were entered concurrently because there was no intention to determine the impact of any single explanatory factor on gestation at termination. STATA version 12 (College Station, Texas 77845 USA) was used to analyse the quantitative data, while the qualitative data were analysed manually.

\subsection{Qualitative Analysis}

All the interviews were transcribed, edited and analyzed in English. Each of the research assistants transcribed the interview recordings before submitting to the author. The data were analysed 
Fred Yao Gbagbo

inductively by identifying main themes. The author first undertook preliminary coding of the data, independently reviewed all codes and, resolution of inconsistencies in the themes.

\section{Results}

\subsection{Quantitative results}

\subsubsection{Profile of the Respondents}

The study found that, women of various profiles had a pregnancy terminated for some reason(s). Young women between the ages of 20-24, women who have never married, the self-employed, women who have no living children, women with secondary level education and those belonging to the Christian faith, were observed as those having the highest induced abortions in the Accra metropolis. About 55 percent of the respondents, prior to having an induced abortion had a secondary level of education. Although all the respondents were noted to have belonged to at least a religious affiliation (i.e. Christians, Moslems, Hindus, Buddhist and African Traditional Religions) statistically religion was not significantly associated with pregnancy termination. Contrary to the Ghanaian culture which generally adores pregnancy and childbirth there were high $(53 \%)$ reported cases of pregnancy termination among women even with those who have no living children. About $42 \%$ of married women in stable relationships also reported to have had abortion(s) in the study area.

Table1. Profile of women who underwent abortion in the Accra metropolis, Ghana

\begin{tabular}{|c|c|c|}
\hline Background Characteristics & Frequency & Percentage \\
\hline \multicolumn{3}{|l|}{ Age group } \\
\hline $15-19$ & 49 & 12.31 \\
\hline $20-24$ & 134 & 33.67 \\
\hline $25-29$ & 111 & 27.89 \\
\hline $30-34$ & 65 & 16.33 \\
\hline $35+$ & 39 & 9.00 \\
\hline Total & 398 & 99.2 \\
\hline \multicolumn{3}{|l|}{ Marital status } \\
\hline Never married & 199 & 50.00 \\
\hline Married/ in union & 167 & 41.96 \\
\hline Previously married & 32 & 8.04 \\
\hline Total & 398 & 100 \\
\hline \multicolumn{3}{|l|}{ Education } \\
\hline None & 27 & 6.73 \\
\hline Primary & 51 & 12.72 \\
\hline Secondary & 221 & 55.11 \\
\hline Higher & 102 & 25.44 \\
\hline Total & 401 & 100 \\
\hline \multicolumn{3}{|l|}{ Religious affiliation } \\
\hline Christian & 326 & 81.30 \\
\hline Moslem & 70 & 17.46 \\
\hline Other & 5 & 1.25 \\
\hline Total & 401 & 100 \\
\hline \multicolumn{3}{|l|}{ Occupational status } \\
\hline Unemployed & 45 & 11.36 \\
\hline Self employed & 148 & 37.37 \\
\hline Student/Apprentice & 134 & 33.84 \\
\hline Other & 69 & 17.42 \\
\hline Total & 396 & 99.99 \\
\hline \multicolumn{3}{|l|}{ Number of living children } \\
\hline 0 & 212 & 53.00 \\
\hline 1 & 78 & 19.50 \\
\hline 2 & 57 & 14.24 \\
\hline 3 & 33 & 8.23 \\
\hline $4+$ & 20 & 5.00 \\
\hline Total & 400 & \\
\hline
\end{tabular}

Source: Field Survey, 2011 


\subsubsection{Gestation at Termination}

The study observed in Figure 1 that the highest percentages of the reported induced abortions occurred within the second month of gestation and among the 15-19 years (about 43\%) and 30-34 years (about $46 \%$ ). Cumulatively, about $76 \%$ of respondents reported to have had an abortion during the first trimester (1-3 months) of pregnancy.

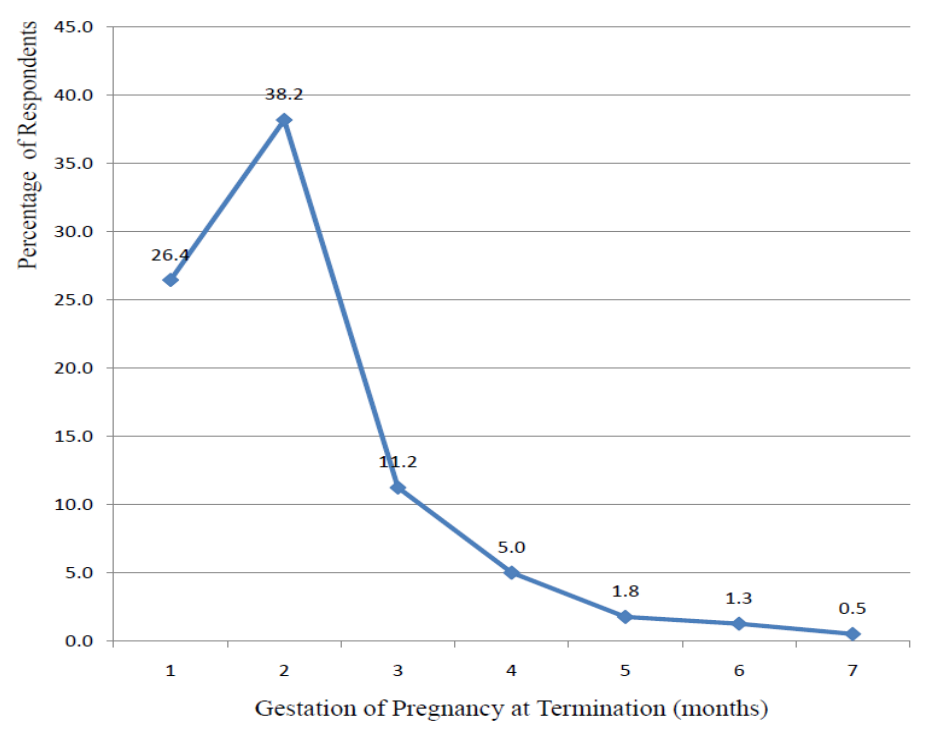

Figure 1: Gestation of Pregnancy at Termination

Source: Field Survey, 2011

\subsubsection{Profile of Pregnant Woman and Gestation at Termination}

In Table 2 it was evident that the gestation at termination was dependent on the profile of respondents. For instance, statistically the age of respondents was significantly $\left(\chi^{2}=32.71 ; p=0.008\right)$ associated with the gestation at termination. Additionally, the marital status of a woman at the time of pregnancy was also significantly associated $\left(\chi^{2}=29.59 ; \mathrm{p}<0.001\right)$ with gestation at termination. The profiles of the respondents informed their initial reaction towards pregnancy when it was first discovered. About 65 percent of respondents were worried and shocked at the time they became pregnant hence the timing for the termination.

Table2. Gestation of Pregnancy Terminated by Profile of women

\begin{tabular}{|c|c|c|c|c|c|}
\hline \multicolumn{6}{|c|}{ Gestation at termination (Months) } \\
\hline Profile of women & $\begin{array}{c}1 \\
(n=106)\end{array}$ & $\begin{array}{c}2 \\
(n=153)\end{array}$ & $\begin{array}{c}3 \\
(n=45)\end{array}$ & $\begin{array}{c}4+ \\
(n=34)\end{array}$ & $\begin{array}{l}\text { Don't knou } \\
(\mathrm{n}=63)\end{array}$ \\
\hline$\%$ Total & 26.43 & 38.15 & 11.22 & 8.48 & 15.71 \\
\hline \multicolumn{6}{|c|}{ Age $\left(\chi^{2}=32.71 ; p=0.008\right)$} \\
\hline $15-19$ & 20.41 & 42.86 & 10.20 & 2.04 & 24.49 \\
\hline $20-24$ & 38.06 & 34.33 & 9.70 & 8.96 & 8.96 \\
\hline $25-29$ & 18.02 & 37.84 & 13.51 & 10.81 & 19.82 \\
\hline $30-34$ & 20.00 & 46.15 & 6.15 & 12.31 & 15.38 \\
\hline $35+$ & 28.21 & 30.77 & 20.51 & 2.56 & 17.95 \\
\hline \multicolumn{6}{|c|}{ Marital status $\left(\chi^{2}=10.18 ; p=0.253\right)$} \\
\hline Never married & 30.15 & 37.69 & 9.55 & 7.54 & 15.08 \\
\hline Married/In union & 20.96 & 38.92 & 14.97 & 8.38 & 16.77 \\
\hline Previously married & 31.25 & 37.50 & 3.12 & 15.62 & 12.50 \\
\hline \multicolumn{6}{|c|}{ Education $\left(\chi^{2}=14.32 ; \mathrm{p}=0.280\right)$} \\
\hline None & 22.22 & 37.04 & 14.81 & 11.11 & 14.81 \\
\hline Primary & 23.53 & 31.37 & 17.65 & 9.80 & 17.65 \\
\hline Secondary & 28.51 & 34.38 & 12.67 & 8.14 & 16.29 \\
\hline Higher & 24.51 & 50.00 & 3.92 & 7.84 & 13.73 \\
\hline \multicolumn{6}{|c|}{ Religious Affiliation $\left(\left(\chi^{2}=10.43 ; \mathrm{p}=0.236\right)\right.$} \\
\hline Christian & 27.61 & 36.65 & 11.04 & 7.98 & 14.72 \\
\hline
\end{tabular}


Fred Yao Gbagbo

\begin{tabular}{|c|c|c|c|c|c|}
\hline Moslem & 22.86 & 37.14 & 11.43 & 11.43 & 17.14 \\
\hline Other & - & 20.00 & 20.00 & - & 60.00 \\
\hline \multicolumn{6}{|c|}{ Occupational status $\left(\chi^{2}=13.24 ; \mathrm{p}=0.351\right)$} \\
\hline Unemployed & 17.78 & 35.56 & 8.89 & 11.11 & 26.67 \\
\hline Self employed & 25.68 & 35.81 & 16.22 & 9.46 & 12.84 \\
\hline Student/Apprentice & 29.10 & 38.06 & 8.96 & 7.46 & 16.42 \\
\hline Other & 27.54 & 44.93 & 7.25 & 7.25 & 13.04 \\
\hline \multicolumn{6}{|c|}{ Number of living children $\left(\chi^{2}=18.47 ; \mathrm{p}=0.297\right)$} \\
\hline 0 & 27.83 & 40.57 & 9.91 & 6.13 & 15.57 \\
\hline 1 & 23.08 & 37.18 & 10.26 & 8.97 & 20.51 \\
\hline 2 & 29.82 & 35.09 & 7.02 & 12.28 & 15.79 \\
\hline 3 & 18.18 & 30.30 & 35.00 & 15.00 & 9.09 \\
\hline $4+$ & 30.00 & 35.00 & 15.00 & 10.00 & 10.00 \\
\hline
\end{tabular}

Source: Field Survey, 2011

Table3. Binary Logistic Regression Model result of Occupation and Gestation at Abortion

\begin{tabular}{|c|c|c|c|c|}
\hline Background Characteristics & Model 1 & $95 \% \mathrm{CI}$ & Model 2 & $95 \% \mathrm{CI}$ \\
\hline \multicolumn{5}{|l|}{ Occupational status } \\
\hline Unemployed (ref) & 1 & {$[1,1]$} & 1 & {$[1,1]$} \\
\hline Employed & 1.467 & [0.488-4.413] & 2.431 & {$[0.705-8.383]$} \\
\hline Student/Apprentice & 1.821 & [0.576-5.764] & 1.655 & [0.483-5.667] \\
\hline Others & 1.964 & [0.524-7.357] & 3.292 & [0.728-14.88] \\
\hline \multicolumn{5}{|l|}{ Marital status } \\
\hline Never married (ref) & & & 1 & {$[1,1]$} \\
\hline Currently married & & & 1.349 & [0.501-3.633] \\
\hline Previously married & & & 0.585 & [0.148-2.308] \\
\hline \multicolumn{5}{|l|}{ Age group } \\
\hline $15-19$ (ref) & & & 1 & {$[1,1]$} \\
\hline $20-24$ & & & 0.240 & [0.0288-2.005] \\
\hline $25-29$ & & & 0.205 & [0.0225-1.872] \\
\hline $30-34$ & & & 0.285 & [0.0254-3.193] \\
\hline $35+$ & & & 2.299 & [0.0994-53.19] \\
\hline \multicolumn{5}{|l|}{ Education } \\
\hline No education (ref) & & & 1 & {$[1,1]$} \\
\hline Primary & & & 0.803 & [0.159-4.053] \\
\hline \multicolumn{5}{|l|}{ Secondary } \\
\hline Higher & & & 0.979 & {$[0.191-5.015]$} \\
\hline \multicolumn{5}{|l|}{ Number of living children } \\
\hline 0 & & & 5.593 & {$[0.571-54.75]$} \\
\hline 1 & & & 3.090 & [0.374-25.51] \\
\hline 2 & & & 2.134 & [0.287-15.88] \\
\hline 3 & & & 0.968 & {$[0.127-7.372]$} \\
\hline 4 (ref) & & & 1 & {$[1,1]$} \\
\hline Cons & $5.600^{* * * *}$ & {$[2.162-14.50]$} & 4.094 & [0.154-108.8] \\
\hline Log likelihood & -109.2 & & -100.7 & \\
\hline Chi-squared & 1.287 & & 17.35 & \\
\hline$N$ & 334 & & 329 & \\
\hline
\end{tabular}

Exponential coefficients; $95 \%$ confidence intervals in brackets ${ }^{*} p<0.05,{ }^{* * *} p<0.01,{ }^{* * *} p<0.001$

Source: Field Survey, 2011

\subsubsection{Occupation and Gestation of Pregnancy at Termination}

The study hypothesis: 'There is no significant association between occupation of a pregnant woman and the gestation period at which a pregnancy is terminated' was tested using binary logistic regression model (Table 3). This hypothesis was first tested with a bi-variate model, focusing only on the dependent variable and the main explanatory variable, thus occupation. Respondents who were not employed were used as the reference category. The results showed that the employed were more likely $(\mathrm{OR}=1.47 ; 95 \% \mathrm{CI}=0.488-4.413)$ to abort within the first trimester than the reference. The same is noted for the students/apprentice and those in the "others" categories as shown in Table 3 (Model 1). In a second model where other possible explanatory variables were included in the model (Table 
3), the odds for the employed and "others" increased in relation to first trimester abortion but remained statistically insignificant. In respect of the model specification, Model 2 of Table 3 slightly fits better than Model 1 in the same Table. This can be observed from the -2log-likelihood of -100.7 compared to -109.2 in Model 1. This implies the smaller the log-likelihood the better the fit. Overall, the hypothesis that there is no significant association between occupation and gestation period at which abortion occurs could not be rejected even after controlling for other covariates.

\subsubsection{Person Responsible for Pregnancy and Gestation at Termination}

In Figure 2, it was noted that the most rapid termination occurred among women impregnated by a rapist or blood relation. There exist some differentials in the figures, which are worth commenting on. Among those impregnated by a rapist or blood relation, more than half (about 57 percent) of them had the termination at one-month gestation period. A similar early termination was observed among those impregnated by their ex-husband with about 40 percent of them having a termination at one-month gestation period. About 50 percent and 44 percent of respondents impregnated by their lecturer/teacher/boss as well as men within the other category of groupings (i.e. clients of commercial sex workers, school mates, church mates etc.) respectively did not go beyond the second month of gestation period, which suggests that the decision and action for the termination was rapid.

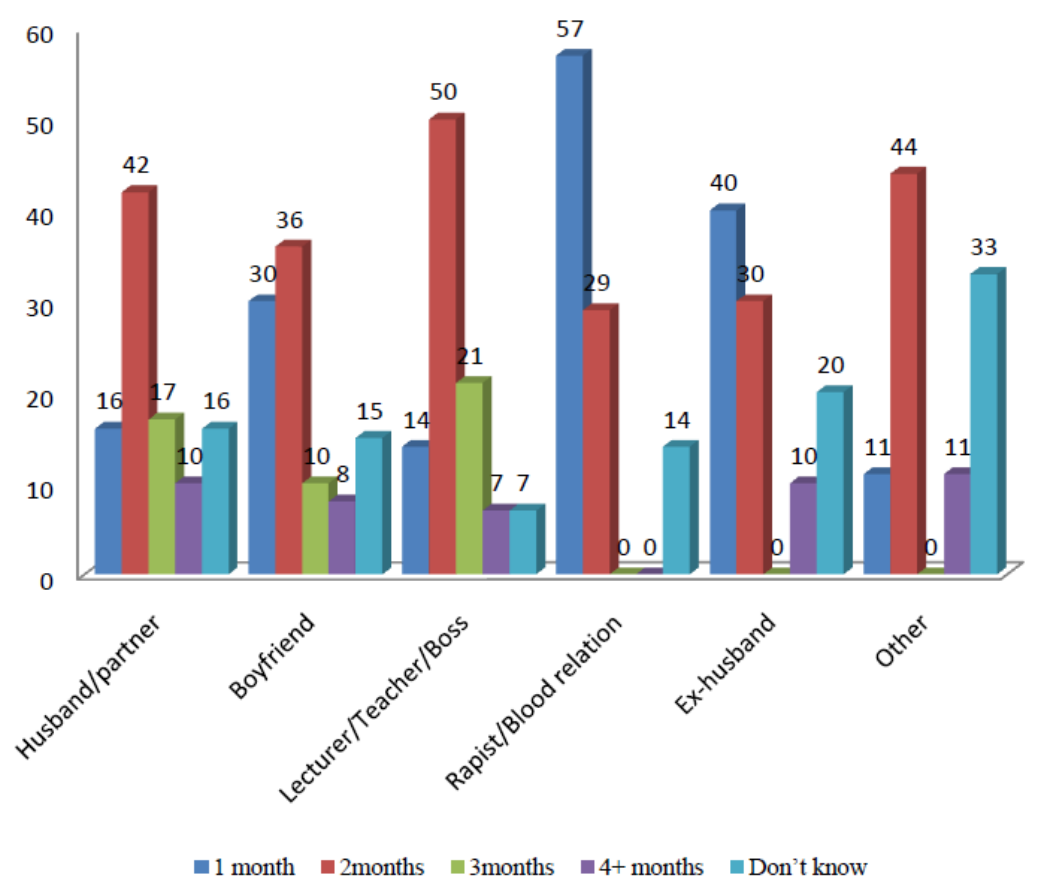

Figure2. Person Responsible for Pregnancy and Gestation at Termination

Source: Field Survey, 2011

\subsection{Qualitative Results}

\subsubsection{Profile of Respondents and Gestation at Termination}

Results from the IDI indicates that the gestation at termination in this study was influenced by the profile of respondents which invariably also had a bearing on circumstances surrounding onset of pregnancy, initial reactions to pregnancy, occupation and perceived socio-economic and health risk to the pregnant woman. In situation where the circumstances surrounding onset of the pregnancy was traumatic, the initial reaction to the pregnancy was hatred hence rapid decisions were taken for an abortion. A respondent in the IDI recounted her experiences as follows:

I was devastated after finding out I had been drugged and raped during my friend's graduation party. My situation became worse when the pregnancy occurred as a result. My initial reaction to all these happenings was guilt and anger because I least expected such a thing to have happened to me after many cautions from my parents to be mindful of such occurrences. The consequences of carrying a premarital pregnancy to our family reputation made me to take a rapid decision of resorting to an abortion without counseling (25 years, Banker). 
Another respondent indicated that:

My course mate raped me one Saturday evening, during a discussion in his room whilst in school. As soon as I realized I had missed my period the following month, I quickly did a pregnancy test to see if it was a pregnancy. When pregnancy was confirmed, I had to go for an abortion without letting anybody know about my predicaments. I kept these all to myself to protect my personal image and the reputation of my family (19 years, student).

\subsubsection{Person Responsible for Pregnancy and Gestation at Termination}

Another observation made during the IDI to have influenced the gestation at termination of a pregnancy was related to a dislike for the person responsible for a pregnancy and the implications of keeping the pregnancy to the respondents. During the in-depth interview, some of the respondents indicated that they had to undergo an early abortion mainly to prevent people from noticing that they were pregnant in order to avoid disgrace and embarrassment to themselves and families. A respondent indicated that:

I least expected my own uncle could do this to me. I had many suicidal thoughts when I became pregnant. I developed deep dislike for my uncle as many issues ran through my mind to revenge his act. Besides, how could my baby have called this shameless uncle if I had carried the pregnancy to term? Thus my mother advised on an abortion at 6weeks gestation (20 years, apprentice).

Another respondent indicated that:

I realized was feeling 'funny' and was told at the hospital that I was two months pregnant. Although this was not too surprising news to me because in the previous months I had had unprotected sexual intercourse with my boyfriend, my boss, and my sugar daddy at separate times. My worry however is not who was responsible for this pregnancy, but all these men were not people I genuinely would like to have a child with. Thus I secretly had an abortion at six weeks gestation (25 years, secretary).

In the case of abortions at advanced gestations, it was noted from the IDI that the decision was not readily taken. Almost all the respondent who resorted to mid trimester abortions did so either on health grounds, on account of gross feotal abnormalities or adverse life events which occurred midway into the pregnancy. A respondent indicated that:

Four months into the pregnancy terminated, my husband and I tested HIV positive during a routine antenatal care. The shock of the news made me so much depressed that I developed uncontrolled high blood pressure which resulted in the termination of the pregnancy at 5 months to safe my life (28 years, Trader).

Another respondent described her ordeal as follows:

Although my husband never complained about our childless marriage for five years after our marriage I really wanted to keep the pregnancy to please my husband. Sadly the consequences of having an abnormal child following a diagnosis of gross feotal abnormality during the fifth month of pregnancy was so devastating that my husband encouraged me after several deliberations for a termination to prevent the frustration of having an abnormal baby as a first child (35years, house wife).

Another respondent told the research team that:

I lost my dear husband and bread winner in a very buzzard situation when I was mid-way pregnant. My entire life came to a standstill and could not figure out what the future will be for me and the two boys that we already have amidst my husband's hostile family. I wept bitterly daily for a month and decided to terminate the five and a half months old pregnancy due to my uncertainty of the future (30 years, housewife).

\subsubsection{Occupation And Gestation of Pregnancy at Termination}

Findings from the IDI unveiled details of the association between respondents' occupation and the gestation at termination. Whereas the pursuit of certain carries mandatorily compelled some pregnant women to have an abortion, others were just a matter of choice. 
A respondent narrated her story as follows:

Two months to finalize arrangement for my enlistment into the police force I realized I was pregnant. My parent really struggled to bring me that far into the enlistment process. Because pregnancy was not allowed in the training school and I did not want to miss the opportunity I had to terminate the pregnancy to make way for my chosen carrier (21 years, police trainee).

Another respondent indicated that:

I have barely clocked the three months mandatory probation period in the aviation industry for my job confirmation. How could I start a carrier as an Air holster with pregnancy although I am married? This did not auger well with my carrier goals thus I terminated the pregnancy at 8weeks gestation (22 years, Air hostess).

Two out of every five respondent interviewed had to terminate their pregnancies in the first trimester because they are final year students in training institutions that do not accept pregnancy whilst in training. Respondents' indicated a wish to carry the pregnancy to term if it was allowed in their training institutions to do so. Indicated below are their experiences:

I was a final year nursing student when I became pregnant and had to terminate it the very first month that I missed my period because; pregnancy in school was punishable offense by dismissal (24years, Nursing student).

Another respondent also reported that:

I was a newlywed final year teacher trainee when I became pregnant. Unfortunately I did not know early because I was still having my regular monthly menses until the third month into the pregnancy. Because; pregnancy was punishable offense by dismissal in the school I had no choice than to have a termination so that I could complete my education (22years, Teacher trainee).

\section{DISCUSSIONS}

Despite the relatively liberal legal and policy environment on induced abortion in Ghana, available evidence from the currently study indicate that women of various profiles use induced abortion as a means to end problems that a pregnancy could aggravate. In this regard, the reasons why some women have abortions at various gestations are personal, diverse and vary across the backgrounds characteristics of women. Some of the most common reasons noted are to postpone childbearing to a more suitable time, gross feotal abnormalities, maternal ill-health or to focus energies and resources on existing children. Others include desire to avoid disruption of one's own education, and not being willing to raise a child conceived as a result of forced or unconsented sex. These factors can sometimes result in compulsory abortion sometimes even at advances gestations. The observation that age of respondents was significantly associated with the gestation period of pregnancy termination and that the highest percentages of the reported induced abortions occurred within the second month of gestation and among the 15-19 years (about 43 percent) and 30-34 years (about $46 \%$ ) suggests that adolescent girls and middle aged women resort to induced abortions when confronted with unplanned pregnancies compared to women in other age groups. For this reason, prevention of unsafe abortion programmes must be tailored at these age groups.

Findings relating to the educational background of respondents and gestations at termination conforms to those of a similar study in Nigeria which indicates that respondents with tertiary education were four times more likely to report an induced abortion, followed by those with secondary level education who were two times more likely to report an induced abortion relative to those without education ${ }^{16}$. Similarly, professional women (teachers and biomedics) who were often better educated were more likely to report an abortion than unemployed women. Divorced, widowed and unmarried women were most likely to report having had an induced abortion among the marriage category ${ }^{17}$. The profiles of abortion seekers from these studies confirms that of the current study which suggest that various factors indeed influence abortion decision-making processes globally. The observation that about $76 \%$ of the terminations occurred in the first trimester reflects the rapid desire to terminate unplanned pregnancies. The expectation was that pregnant women who are students/apprentices are more likely to have an abortion at an early gestation period than women of other occupation categories. This expectation in the case of students and apprentices was supported by a media report on the prohibition of pregnancy in Ghanaian schools or during apprenticeship ${ }^{18}$. For instance on the first of March 2011 at 12: 30 pm a local FM station (Adom FM) in Ghana reported that: 
The Ghana Education Service has backed the decision by authorities of Aduman Senior High School in the Afigya-Kwabre District of the Ashanti Region to sack 17 female students from the school for getting pregnant. According to the radio report the Deputy Director of Education, said that the decision to send the girls home, is in line with the Ghana Education Service policy.

With such a stringent policy, women who become pregnant or think they are pregnant whilst in school would prefer an early first trimester abortion regardless of any limitation to avoid sanctions that could result into dismissal from school leading to embarrassment. The challenge with such decisions is that some of these women although might have missed their periods could not have been pregnant after all. In a similar study, histo-pathological reports from some Nigerian fertility hospitals in 2003 indicated that most women seeking induced abortion services were not after all pregnant at the time of decision-making for an induced abortion ${ }^{20}$. This finding underscores the desperations of women getting rid of unwanted pregnancies and the over zealousness of abortionist doing everything possible to satisfy the request of such people desiring termination of their unwanted pregnancies by all means and at all cost to cecum to a societal pressure. Findings from IDI, also supports some previous abortion studies ${ }^{19,20,21}$ which indicated that the exceptions of pregnancies emanating from rape, incest and defilement are understandable basis for an induced abortion, especially, since these are sexual offences and violent acts, which are usually committed without the consent of a victim who, it is assumed, would experience some immediate psychological distress, hence the rapid decision for abortion.

Although the decision for mid-trimester abortion (abortion at 4+ months) was observed as a difficult decision for the respondents during the IDI, It was evident from the current study that such a decision was taken to escape situations that could have aggravated and/or negatively affected respondents' health, and social lives. The study ascertained that pregnancies terminated at advanced gestations are usually wanted initially but a decision to have such pregnancies terminated emanates from situations beyond a woman's control of which to the pregnant woman, the perceived benefits for such late terminations outweighs those of keeping the pregnancies. The high percentage (about 76 percent) of induced abortion observed within the first trimester (1-3 months gestation) compared to a relatively lower percentage of about 1.8 percent of the reported pregnancies terminated were close to term (6-7 months). The decreasing percentages of respondents who had late abortions imply that abortion decisions are predominantly taken early and that late abortions are last resorts. It can also be deduced from the trends observed in gestations at termination that the bigger the gestational age at the time of abortion decision-making; the less likely it was for a pregnancy to be terminated. Just like previous studies ${ }^{23,24}$, Concerns about carrier development and gestations at termination of pregnancy were also noted in the current study. Observations made from the test of hypothesis looking at association between occupation and gestations at which abortion occurs could not be rejected even after controlling for other covariates. This suggests that young carrier women are most likely to seek first trimester abortions when pregnant. It is therefore important that education on abortion decision making be tailored to meet the different needs of various categories of women in Ghana.

\section{Conclusion}

The gestation at pregnancy termination in this study saw an individual position of fear of the unknown and/or frustration of carrying a pregnancy that a woman perceives as problematic. Women therefore need education and support on gestations for safe abortion as permitted by the Ghanaian abortion law. Ultimately, public health policies and women's right dialogues should frown on workplace/institutional sanctions on pregnancy that push women to have an abortion against their wish and regardless of any limitation to achieve their carrier and reproductive intentions. This may contribute directly to a decrease in unsafe abortion in Ghana.

\section{COMPETING INTERESTS}

The author declares that there are no competing interests.

\section{ACKNOWLEDGMENTS}

The author is grateful to all of the participants for sharing with him their personal experiences and colleagues who reviewed the draft manuscript. 


\section{REFERENCES}

[1] Sedgh, G.; Singh, S.; Shah, I. H.; Åhman, E.; Henshaw, S. K.; Bankole, A. (2012). "Induced abortion: Incidence and trends worldwide from 1995 to 2008" (PDF). The Lancet 379 (9816): 625-632. doi:10.1016/S0140-6736(11)61786-8. PMID 22264435

[2] Åhman, E., \& Shah, I. (2002). Unsafe Abortion: Worldwide Estimates for 2000, Reproductive Health Matters, 19: 13-17.

[3] Åhman, E., \& Shah, I. (2004). Unsafe Abortion: Global and Regional Estimates of the Incidence of Unsafe Abortion and Associated Mortality in 2000. Fourth ed., Geneva: World Health Organization.

[4] World Health Organization (2012). Abortion Statistics by the World Health Organization. Accessed from http://www.worldometers.info/abortions/ on $21^{\text {st }}$ September, 2012.

[5] United Nations Population Fund (1999). International Conference on Population and Development, $(I C P D+5)$. Conference Report.

[6] Boland, R.; Katzive, L. (2008). "Developments in Laws on Induced Abortion: 1998-2007". International Family Planning Perspectives 34 (3): 110-120. doi:10.1363/ifpp.34.110.08. PMID 18957353.

[7] Pastor Mark Driscoll (18 October 2013). "What do 55 million people have in common?". Fox News. Retrieved 2 July 2014.

[8] Dale Hansen (18 March 2014). "Abortion: Murder, or Medical Procedure?". Huffington Post. Retrieved 2 July 2014

[9] Sifris, Ronli Noa (2013). Reproductive Freedom, Torture and International Human Rights Challenging the Masculinisation of Torture. Hoboken: Taylor and Francis. p. 3. ISBN 9781135115227

[10] Provisional National Defense Council (PNDC). Law 102: The Criminal Code (Amendment) Law. The Constitution of Ghana; 1985. Accra: State Publishers.

[11] Quansah-Asare, G. (2008). Induced abortion in Ghana. Presentation at National Health Summit, Ghana

[12] Gbagbo, F.Y. (2006, July 8). Abortion-related Deaths are Preventable. Daily Graphic, pp. 11.

[13] Henry R, Fayorsey C: Coping with Pregnancy: Experiences of Adolescents in Ga Mashi, Accra. Calverton, Maryland, USA: Marco; 2002.

[14] Ghana Statistical Service. (2002). Population and Housing Census 2000: Special Report on 20 Largest Localities in Ghana, Accra: The GSS

[15] Ghana Health Service. (2007). Induced Abortion. Reproductive and Child Health Department of the Family Health Division: 2007 Annual Report

[16] Marie Stopes International Ghana, (2006). Health Sector Research Report. prepared for Marie Stopes International, October 2006

[17] Pathfinder International Ghana: Community Survey Questionnaire on Knowledge, Attitude, and Practice of Abortion for Women 15-49 Years; 2007.

[18] Nyarko P, Adohinzin C, Ramarao S, Ajayi A: Profile of Abortion Seekers in Ghana and their Decision-Making Processes. New York: Population Council; 2008.

[19] Population Council. (1996). Women's Experiences of Unwanted Pregnancy and Induced Abortion in Nigeria. In Robert H. Ebert Program on Critical Issues in Reproductive Health pp 35. One Dag Hammarskjold Plaza. New York, USA.

[20] Nana P.N, Fomulu J.N., \& Mbu R.E. (2005). A four-year retrospective review of post abortal surgical complications at a Central Maternity Yaounde, Cameroon. Clinics in Mother and Child Health. 2(2): 349-63

[21] Adom FM. Ghana Education Service policy backs dismissal of 17 female students for becoming pregnant whilst in school. March 2011 at 12: 30 pm

[22] Morhee, R.A.S., \& Morhee, E.S.K. (2006). Overview of the Law and Availability of Abortion Services in Ghana. Ghana Medical Journal, 40(3): 80-86. 
[23] Sena, K. (2006). Maternal Mortality in Ghana: Seminar Presentation at School of Public Health, University of Ghana, Legon.

[24] Turkson, R.B. (2006). Legal and Policy Aspect of Comprehensive Abortion Care in Ghana. Paper presented at Stakeholders workshop on Abortion Care in Erata Hotel, Accra, Ghana, April, 2006

[25] Ekanem, A.D., Etuk, S.J., Udoma, E.J., \& Ekanem, I.A. (2003). Fertility Profile following induced abortion in Calabar, Nigeria. Tropical Journal of Obstetrics and Gynaecology, 20:89-92.

[26] Culwell KR, Vekemans M, de Silva U, Hurwitz M (July 2010). "Critical gaps in universal access to reproductive health: Contraception and prevention of unsafe abortion". International Journal of Gynecology \& Obstetrics 110: S13-16. doi:10.1016/j.ijgo.2010.04.003. PMID 20451196

[27] Ghana Health Service. (2005). A strategic assessment of comprehensive abortion care in Ghana: Priority setting for reproductive health in the context of health sector reforms in Ghana, Occasional paper 